\title{
Cytotoxicity and Oral Acute Toxicity Studies of Litsea glutinosa C. B (ROB) Stem Bark Ethanol Extract
}

\author{
Arunodaya Hosahalli Sumithregowda, Krishna Venkatarangaiah, Kumaraswamy Malleshappa Honnenahally, \\ Vinaykumar Nagenahalli Manjunath
}

\section{Arunodaya Hosahalli Sumithregowda, Krishna Venkatarangaiah*, Ku- maraswamy Malleshappa Honnenahally, Vinaykumar Nagenahalli Manjunath Department of PG Studies and Research in Biotechnology, Kuvempu University, Shankaraghatta 577 451, Shivamogga, Karnataka, INDIA}

Correspondence

Krishna Venkatarangaiah

Professor, Department of PG Studies and Research in Biotechnology, Kuvempu University, Shankaraghatta 577451 , Shivamogga, Karnataka, INDIA

Phone no: +919448681856

E-mail: krishnabiotech2003@gmail.com

History

- Submission Date: 12-06-2017

- Review completed: 11-07-17:

- Accepted Date: 01-08-2017

DOI : 10.5530/pj.2017.6.138

Article Available online

http://www.phcogj.com/v9/i6

Copyright

(c) 2017 Phcog.Net. This is an openaccess article distributed under the terms of the Creative Commons Attribution 4.0 International license.

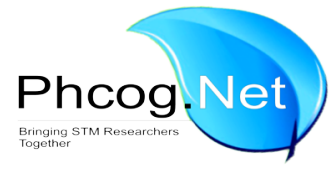

\begin{abstract}
Background: Litsea glutinosa (Lauraceae) stem bark is widely used in folk medicine as a hepatoprotective, anti-diarrheal and anti-dysenteric drug but there is a lack of information about its toxicity. Objective: To evaluate cytotoxicity and acute toxicity of the stem bark ethanol extract (BEE). Materials and Methods: In vitro cytotoxicity of BEE was measured against breast adenocarcinoma, prostate, and colon carcinoma cell lines. In the acute toxicity tests, rats received oral doses of BEE as 1000,2000, and $3000 \mathrm{mg} / \mathrm{kg}$ body weight. Mortality, signs of toxicity, body weight, food consumption, and gross findings were observed for 14 days. Blood samples were collected from anesthetized animals and used for hematological and biochemical parameters. Histopathological study was performed using liver and kidney samples. Results: The BEE does not show significant cytotoxic effect against the tested cell lines up to the range from 5 to $320 \mu \mathrm{g} / \mathrm{ml}$. In acute toxicity study, also lethality was not observed up to $3000 \mathrm{mg} / \mathrm{kg}$ b.w. No significant differences were noticed in body and organ weights and histopathology examinations between the control and treated groups. Conclusion: This study authenticates stem BEE may contain bioactive compounds of potential therapeutic significance which are relatively safe from toxic effects, and evidences the medicinal use of this plant in folk medicine.

Key words: Acute toxicity, Litsea glutinosa, MTT assay, Breast adenocarcinoma cell line, Haematology.
\end{abstract}

\section{INTRODUCTION}

Medicinal plants from time immemorial have been the backbone of traditional medicine and are widely used to treat acute and chronic diseases. The demand for such medicines is increasing day by day for the management and treatment of various health problems. ${ }^{1}$ Despite this rapid growth, there is limited evidence for the effectiveness and toxicity of such medicines; much more needs to be done to validate the ethnopharmacological claims with an evidence base for phytomedicines, botanicals, and all-natural folklore-originated medicines. However, few studies have addressed the toxicity of natural plants, although many questions have been raised regarding their safety. ${ }^{2,3}$ The importance of plant species for therapeutic applications is well established but studies on certain plant-induced toxicity are scarce. However, the rationale for the utilization of medicinal plants has rested largely on long-term clinical experience with little or no scientific data on their efficacy and safety. ${ }^{4}$

Chemotherapy is one of the potential treatments for prolonging the patient's life. Almost $60 \%$ of anticancer drugs are of natural origin, such as plants (i.e., camptothecines, irinotecan, and vincristine) and microorganisms (i.e., bleomycin, dactinomicines, doxorubicin and mitomycin). ${ }^{5}$ However, many chemotherapeutic drugs are presently placed in a predicament of reduced therapeutic effect due to the problem of drug-resistance. ${ }^{6}$ Chemotherapeutic drugs also exert toxicity to normal cells, which in turn causes the unpleasant side effects to the patients. For these reasons, research and development of new classes of anticancer agents which exhibit efficient and selective toxicity in tumour cells are enticing increased attention.

Presently, herbal medicines are gaining interest because of their cost effective and eco-friendly attributes. ${ }^{7}$ L. glutinosa C.B. Rob is an evergreen tree species belonging to the family Lauraceae. The traditional practitioners residing near Bhadra Wild Life Sanctuary of the Western Ghats are using the stem bark extract to cure alcoholism-related liver disorders.

The leaves are aromatic and mucilaginous used in diarrhea and dysentery as well as for the treatment of wounds and bruises. ${ }^{8-10}$ The leaves and berries yield an essential oil which is used by traditional practitioners in the treatment of rheumatism. ${ }^{11}$ The previous investigators have reported the pres-

Cite this article: Arunodaya HS, Venkatarangaiah K, Kumaraswamy HM, Vinaykumar NM. Cytotoxicity and Oral Acute Toxicity Studies of Litsea glutinosa C. B (ROB) Stem Bark Ethanol Extract. Pharmacog J. 2017;9(6):880-6. 
ence of phytoconstituents: Tannin, $\beta$-sitosterol, boldine, norboldine, laurotetanine, n-methyl laurotetanine, n-methylactinodaphnine, sebiferine, litseferine from the methanol extract of the bark. ${ }^{8-11,12}$ However, scanty data are available on the cytotoxicity and lethal toxicity of this species. But in traditional medicine the leaves and stem bark aqueous extract administered orally to the patients for diarrhea and dysentery. Considering ethnopharmacological applications of the plant, the investigation was undertaken to assess the toxic effects of BEE using male Albino rats and ATCC cancer cell lines.

\section{MATERIALS AND METHODS}

\section{Plant materials}

The stem bark of L. glutinosa was harvested from Kuvempu University campus, Karnataka, India, in December 2013 and was identified by Dr. Tariq Husain, Head and Scientist, Biodiversity and Angiosperm Taxonomy, National Botanical Research Institute, Lucknow, India, where the voucher specimen was deposited (No. 97294).

\section{Preparation of L. glutinosa ethanol extract}

The plant sample was ground to a coarse powder, subjected to sequential extraction using hot Soxhlet extraction technique. The extract was filtered through Whatman paper no. 1 and then concentrated using rotary flash evaporator (Buchi, Flawil, Switzerland). The yield of the ethanol extract was $23.7 \%$ based on dry weight. The dried residue of plant extract was resuspended in Mili-Q water for further biological assay.

\section{Cytotoxicity assay}

In vitro cytotoxic activity was performed to determine cell viability by measuring the metabolism of tetrazolium substrate MTT. The effect of BEE was assessed against breast adenocarcinoma cell line (MDAMB-231), prostate cancer cell line (DU145) and colon carcinoma cell lines (HCT-116).

Cells were seeded into triplicate wells of 96-well microplate at a density of $4 \times 10^{4}$ viable cells $/ \mathrm{ml}$. Cells were incubated with BEE at different concentrations ranging from $5-320 \mu \mathrm{g} / \mathrm{ml}$ along with a parallel control for $24 \mathrm{~h}$ at $37^{\circ} \mathrm{C}$ and the medium was aspirated and replaced with $100 \mu \mathrm{l}$ of MTT ( $5 \mathrm{mg} / 10 \mathrm{ml}$ of MTT in 1X PBS) in each well. The culture plates were mixed gently, incubated for $4 \mathrm{~h}$. The blue formazan crystals being formed within cells were solubilized with $100 \mu \mathrm{l}$ of DMSO and absorbance of blue formazan was determined at $590 \mathrm{~nm}$ in an automated plate reader. Percentage inhibition of the growth was calculated and expressed as mean \pm SEM. $\mathrm{IC}_{50}$ of the BEE on different cell lines were calculated from the concentration $\mathrm{v} / \mathrm{s}$ percentage inhibition curves. ${ }^{13}$

\section{Experimental animals}

Male Albino rats of Wistar strain, weighing about 160-220 g was used for the acute toxicology studies. The animals were acclimatized to laboratory conditions for 14 days prior to the experiments. The rats were maintained at a room temperature of $22-24^{\circ} \mathrm{C}$, with $12 \mathrm{~h}$ light/dark cycle. During acclimatization, animals were housed in polycarbonate cages with a standard pellet diet and water ad libitum. The food pellets for the experimental animals were purchased from Scientist's Choice Laboratory animal feed, Chennai, India. All procedures in this study were performed according to the guidelines of the CPCSEA (REG.NO.144/1999/ CPCSEA/dtd:10/04/2000). The experimental protocol was approved by the Institutional Ethical Committee (Reg. No: NCP/IAEC/CL/242/201314).

\section{Acute oral toxicity study}

Acute toxicity test was performed according to the Organization of Economic Cooperation and Development (OECD) guideline 423 for testing of chemicals. ${ }^{14}$ In the sighting study, an overnight fasted male rat was administered orally with a single dose of 1000, 2000 and $3000 \mathrm{mg} / \mathrm{kg}$ BEE prepared in Mili-Q water, whereas, the control group received only Mili-Q water as a vehicle. After administration of L. glutinosa BEE, rats were observed for $24 \mathrm{~h}$, with special attention given to the first $4 \mathrm{~h}$ and once daily further for a period of 14 days. The rats were weighed and visual observations for mortality, behavioural pattern (weakness, aggressiveness, diarrhea, salivation, discharge from eyes and ears, noisy breathing, changes in locomotor activity, clonic convulsion, fur, lethargy, and sleep), changes in physical appearance, injury, pain, and signs of illness were conducted once daily during the period. At the termination day, animals were sacrificed under mild anesthesia and blood sample was collected through the retro-orbital puncture into a sterilized centrifuge tubes and EDTA-containing AcCuvet-PLUS non-vacuum blood collection tube (Peerless Biotech Pvt. Ltd.) for biochemical and hematological analyses, respectively. b.w. and weight of the organs from the control and the test groups were measured and recorded. The relative organ weight of each animal was then calculated as follows. Relative organ weight: (absolute organ weight $\times 100 \%$ )/ body weight of rat on the day of sacrifice..$^{15,16}$

\section{Haematological and biochemical analysis}

The haematological parameters measured were hemoglobin (HB), total count, polymorphonuclear leukocytes, lymphocytes, eosinophils, monocytes, red blood cells (RBC), packed cell volume (PCV), mean corpuscular volume $(\mathrm{MCV})$, mean corpuscular hemoglobin $(\mathrm{MCH})$, mean corpuscular hemoglobin concentration (MCHC), and platelets. The biochemical parameters such as alanine aminotransferase (ALT), aspartate aminotransferase (AST), alkaline phosphatase (ALP), bilirubin total, bilirubin direct, creatinine, urea, total cholesterol (TC), triglycerides (TG), glucose and total protein were estimated in the serum of experimental animals using assay kits and which were obtained from the Robonik India Pvt. Ltd, New Mumbai. The haematological parameters were determined using semi-automated haematology analyzer (Sysmex, Hamburg, Germany) and serum biochemistry tests were performed using semi auto-analyzer (Robonik India Pvt. Ltd., New Mumbai).

\section{Histopathological study}

After sacrificing the rats, all the vital organs heart, kidneys, liver, lung and spleen were autopsied and examined macroscopically for any lesions or abnormalities. ${ }^{17}$ The liver and kidney tissues were washed with normal saline and fixed immediately in $10 \%$ formaldehyde buffer for a period of $18 \mathrm{~h}$. The tissues were dehydrated in graded (50-100\%) ethanol, followed by washing with xylene. Paraffin $\left(56-58^{\circ} \mathrm{C}\right)$ embedding was done at $58 \pm 1^{\circ} \mathrm{C}$ for $4 \mathrm{~h}$ and sections of $5 \mu \mathrm{m}$ were taken using a rotary microtome. The sections were deparaffinised with alcohol xylene series, stained with haematoxylin-eosin dye for photo-microscopic observation, mounted in DPX with a cover slip and histological changes were observed and photographed under Nikon microscope (Model-YS2-H, Japan) at 40X magnification and images were processed in Nikon DSLR Camera (Model-D5100, Japan). The microscopic features of the organs were compared with the control group..$^{18}$

\section{Statistical analysis}

All values are expressed as mean \pm SEM. Comparisons between groups were performed using one-way analysis of variance (ANOVA) followed by Dunnett's multiple comparison tests using GraphPad Prism (version 5) statistical software.

\section{RESULTS}

\section{Cytotoxicity assay}

MTT assay studies revealed that BEE does not show any cytotoxic effect on breast adenocarcinoma cell line, prostate cancer cell line and colon 
carcinoma cell line. The percentage of inhibition of cell proliferation was less than $50 \%$ and the data is shown in the Figure 1.

\section{Acute toxicity tests}

L. glutinosa stem BEE extract at a tested dose of 1000, 2000 and 3000 $\mathrm{mg} / \mathrm{kg}$ b.w. had no adverse effect on the behavioral responses of the tested rats up to 14 days. Physical observations also indicated no signs of behavioural pattern (weakness, aggressiveness, diarrhea, salivation, discharge from eyes and ears, noisy breathing, changes in locomotor activity, clonic convulsion, fur, lethargy, and sleep), changes in physical appearance, injury, pain, and signs of illness of the rats. There was no mortality and weight loss observed at all the tested doses Figure 2 and no significant differences observed in the relative organ weights Table 1.
However, slight weight differences $(\mathrm{P}<0.05)$ were seen in the liver and heart of the animals treated with $3000 \mathrm{mg} / \mathrm{kg}$ of the extract.

\section{Haematological and biochemical analysis}

The haematological parameters such as $\mathrm{HB}$, total count, polymorphonuclear leukocytes, lymphocytes, eosinophils, monocytes, RBC, PCV, MCV, $\mathrm{MCH}, \mathrm{MCHC}$, and platelets did not show any significant differences between the control and BEE treated groups at all test doses, Table 2. Likewise, there was no statistically significant differences observed in the biochemical parameters such as, ALT, AST, ALP, bilirubin total, bilirubin direct, creatinine, urea, TC, TG, glucose and total protein were found to be in normal range for all animals at the end of the study Table 3.
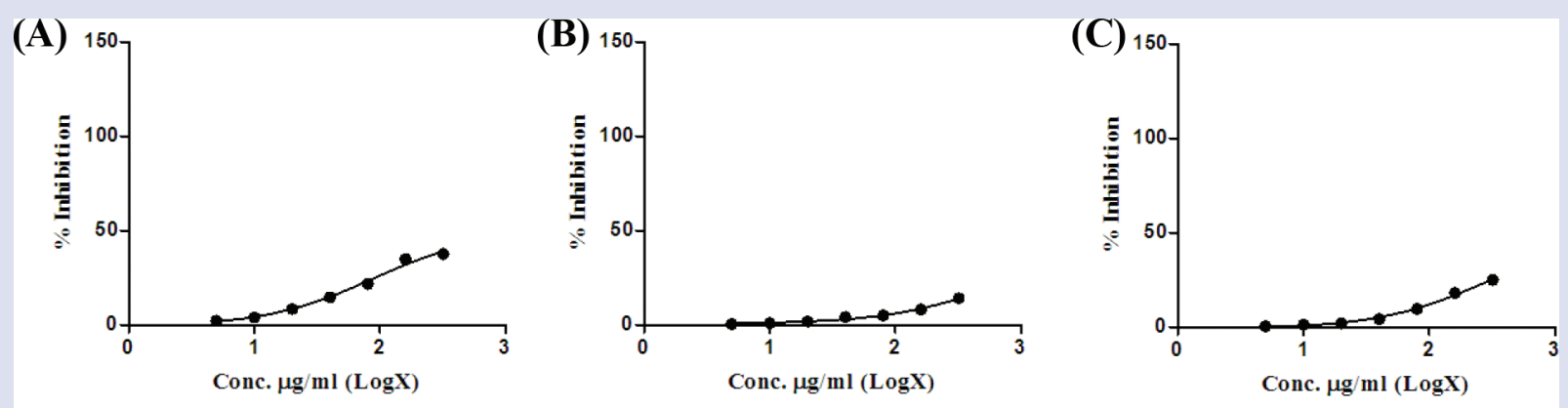

Figure 1: Dose-response relationship curve of the stem bark ethanol extract of $L$. glutinosa against A: Brest adenocarcinoma cell line (MDA-MB-231), B: Prostate cancer cell line (DU145), and C: Colon carcinoma cell line (HCT-116).

\begin{tabular}{|c|c|c|c|c|}
\hline Organ & Control & BEE-1000 mg/kg b.w. & BEE-2000 mg/kg b.w. & BEE-3000 mg/kg b.w. \\
\hline Liver & $2.81 \pm 0.09$ & $3.13 \pm 0.06^{\mathrm{ns}}$ & $2.90 \pm 0.02^{\mathrm{ns}}$ & $3.27 \pm 0.15^{\star}$ \\
\hline Kidney & $0.56 \pm 0.01$ & $0.58 \pm 0.02^{\mathrm{ns}}$ & $0.60 \pm 0.03^{\mathrm{ns}}$ & $0.57 \pm 0.04^{\mathrm{ns}}$ \\
\hline Lung & $0.63 \pm 0.09$ & $0.75 \pm 0.03^{\text {ns }}$ & $0.83 \pm 0.11^{\mathrm{ns}}$ & $0.74 \pm 0.11^{\mathrm{ns}}$ \\
\hline Spleen & $0.47 \pm 0.03$ & $0.50 \pm 0.07^{\mathrm{ns}}$ & $0.36 \pm 0.15^{\mathrm{ns}}$ & $0.40 \pm 0.07^{\mathrm{ns}}$ \\
\hline Heart & $0.29 \pm 0.01$ & $0.34 \pm 0.003^{\text {ns }}$ & $0.33 \pm 0.01^{\mathrm{ns}}$ & $0.39 \pm 0.01^{* *}$ \\
\hline Body weight (gm) & $213.2 \pm 9.44$ & $211.0 \pm 7.75$ & $211.2 \pm 3.56$ & $207.3 \pm 1.33$ \\
\hline
\end{tabular}

Values are expressed as mean \pm SEM ( $\mathrm{n}=3$ for each group). ${ }^{\star} \mathrm{P}<0.05,{ }^{*} \mathrm{P}<0.01,{ }^{* *} \mathrm{P}<0.001$ were considered significant. Asterisks denote significant difference compared to control.

BEE: Bark ethanol extract; ns: Not significant.

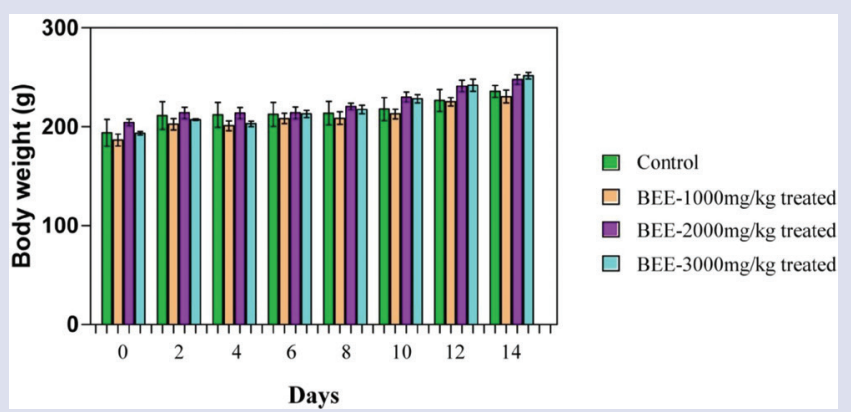

Figure 2: Mean body weight of rats receiving stem bark ethanol extract of $L$. glutinosa. Values are expressed as mean \pm SEM $(n=3$ for each group).

\section{Macropathology and Histopathology}

Macroscopic observation of the vital organs of BEE treated animals also revealed no abnormalities in the colour or texture when compared with the organs of the control group. The microscopic examination of the transverse section of liver and kidney of the control and BEE treated group rats are shown in Figure 3. Histopathological examination of the control group and BEE treated rats showed normal architecture and absence of any gross pathological lesion in organs. The $\mathrm{LD}_{50}$ of this plant was therefore estimated to be more than $3000 \mathrm{mg} / \mathrm{kg}$.

\section{DISCUSSION}

Natural products including their derivatives and analogues still represent a major part of therapeutic alternatives. ${ }^{19}$ The consumers believe that traditional herbal remedies are safe, whereas, they could cause some adverse effects so their safety and efficacy evaluation is required. ${ }^{20}$ The 


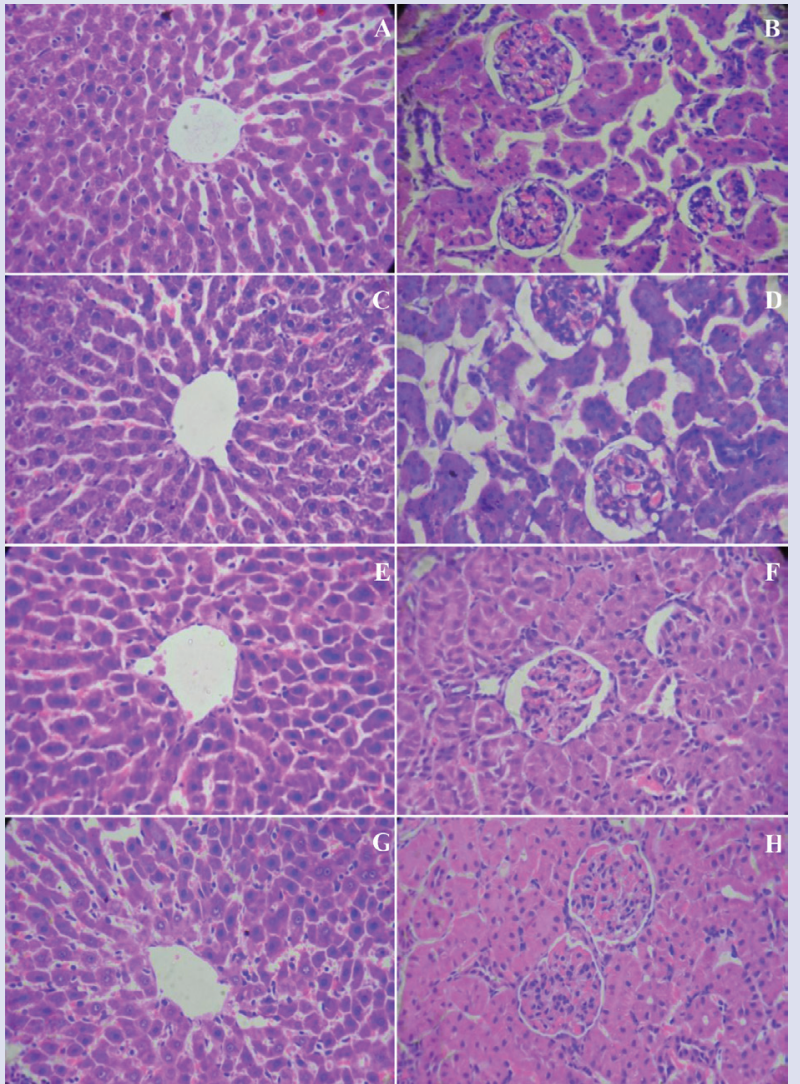

Figure 3: Histopathological picture of liver and kidney of control and treated groups of animals. (A) \& (B) Section of liver \& kidney from control animals showed normal liver architecture composed of normal sinusoidal pattern and normal hepatocytes and normal sizes of glomeruli with normal tubules, respectively; (C), (D), (E), $(F),(G)$ and $(H)$ Section of liver and kidney from rats treated with L. glutinosa 1000, 2000, and $3000 \mathrm{mg} / \mathrm{kg}$ body weight exhibited normal architecture of hepatocytes and normal sizes of glomeruli with normal tubules indicating safety of the extract ( $40 \mathrm{X}$ magnification). main purpose of toxicity study is to establish the adverse effect caused by the phytochemicals, investigate any possible dose-effect relationship and to identify the responsible phytochemicals causing the toxicity. The pharmacological effects of L. glutinosa were reported in previous studies. ${ }^{10}$ The present study was conducted to evaluate the possible cytotoxicity and acute oral toxicity of stem BEE of this plant.

The American National Cancer Institute (NCI) guidelines set the limit of activity for crude extracts at $50 \%$ inhibition $\left(\mathrm{IC}_{50}\right.$ ) of proliferation of less than $30 \mathrm{mg} / \mathrm{ml}$ after an exposure time of $24 \mathrm{~h} .{ }^{21} \mathrm{IC}_{50}$ values below this stringent point have not been noted with any of the three studied cancer cell lines. The BEE does not inhibit the proliferation of the tested cancerous cells up to the level of 50\%. This suggests that the constituents of the BEE do not induce cytotoxic effect on the tested cancerous cell lines. However, the previous investigators reported the cytotoxic property of L. glutinosa stem bark chemicals against the selected cancerous cell lines. Wang et al., ${ }^{22}$ evaluated the cytotoxic effect of leaves and twigs of L. glutinosa against myeloid leukemia HL-60, hepatocellular carcinoma SMMC-7721, lung cancer A-549, breast cancer MCF-7 and colon cancer SW480 cells for which it was proved to be inactive $\left(\mathrm{IC}_{50}>40 \mathrm{mM}\right)$. The present study also shows that the stem BEE of L. glutinosa was found to be inactive against adenocarcinoma, prostate cancer and colon carcinoma ATCC cell lines. Even at the concentration of $5-320 \mu \mathrm{g} / \mathrm{ml}$ the BEE was found to be inactive against the selected cancerous cell lines. On the contrary, Agrawal et al. ${ }^{23}$ reported methanol extract of the heartwood of L. glutinosa showed significant cytotoxic activity. This is due to the biosynthesis and accumulation of phytoconstituents at different region of the plant parts and toxic specificity of the compounds against the selected cell lines.

The traditional practitioners of this area orally administered the stem bark extract to cure liver diseases (Jaundice), diarrhea and dysentery ${ }^{10-24}$ it was also noticed that the patients did not show any symptoms of irritability and behavior patterns such as tremors, salivation, and diarrhea. To authenticate the nontoxic effect of BEE acute toxicity experiment was conducted on albino rats. No mortality was recorded during the sighting as well as in main study and the stem BEE doses of 1000,2000 , and $3000 \mathrm{mg} / \mathrm{kg}$ b.w. did not produce significant changes in behavior, b.w. gain or loss, food and water consumption, breathing, and gastrointestinal effects in rats. The b.w. changes serve as a sensitive indication of the general health status of animals. ${ }^{25}$ However, weight

Table 2: Effect of Litsea glutinosa stem bark ethanol extract on haematological parameters in acute oral toxicity study.

\begin{tabular}{|c|c|c|c|c|c|}
\hline \multirow[b]{2}{*}{ Test } & \multirow[b]{2}{*}{ Unit } & \multirow[b]{2}{*}{ Control } & \multicolumn{3}{|c|}{ Litsea glutinosa stem bark ethanol extract } \\
\hline & & & Test $1000 \mathrm{mg} / \mathrm{kg}$ & Test $2000 \mathrm{mg} / \mathrm{kg}$ & Test $3000 \mathrm{mg} / \mathrm{kg}$ \\
\hline HB & $\mathrm{g} / \mathrm{dL}$ & $10.65 \pm 0.37$ & $13.60 \pm 0.28^{\star}$ & $11.80 \pm 1.32^{\text {ns }}$ & $11.90 \pm 1.09^{\mathrm{ns}}$ \\
\hline Total count & $10^{3} / \mu \mathrm{l}$ & $13500 \pm 1589$ & $18467 \pm 5272^{\mathrm{ns}}$ & $14467 \pm 3700^{\text {ns }}$ & $15800 \pm 1914^{\mathrm{ns}}$ \\
\hline PNL & $10^{3} / \mu \mathrm{l}$ & $35.00 \pm 6.42$ & $36.33 \pm 3.48^{\mathrm{ns}}$ & $45.33 \pm 2.90^{\mathrm{ns}}$ & $45.33 \pm 8.96^{\mathrm{ns}}$ \\
\hline Lymphocytes & $10^{3} / \mu \mathrm{l}$ & $60.67 \pm 3.48$ & $64.33 \pm 3.84^{\mathrm{ns}}$ & $55.67 \pm 3.38^{\mathrm{ns}}$ & $59.00 \pm 6.35^{\text {ns }}$ \\
\hline Eosinophils & $10^{3} / \mu \mathrm{l}$ & $1.33 \pm 0.33$ & $1.000 \pm 0.57^{\mathrm{ns}}$ & $0.66 \pm 0.33^{\mathrm{ns}}$ & $1.000 \pm 0.0^{\mathrm{ns}}$ \\
\hline Monocytes & $10^{3} / \mu \mathrm{l}$ & $0.33 \pm 0.33$ & $0.0 \pm 0.0^{\mathrm{ns}}$ & $0.66 \pm 0.33^{\text {ns }}$ & $1.000 \pm 0.0^{\mathrm{ns}}$ \\
\hline RBC & $10^{6} / \mu \mathrm{l}$ & $6.26 \pm 0.31$ & $7.63 \pm 0.49^{\mathrm{ns}}$ & $7.40 \pm 0.56^{\mathrm{ns}}$ & $8.20 \pm 0.20^{*}$ \\
\hline PCV & $\%$ & $38.97 \pm 2.56$ & $46.50 \pm 1.18^{\mathrm{ns}}$ & $41.70 \pm 2.42^{\mathrm{ns}}$ & $45.17 \pm 0.53^{\mathrm{ns}}$ \\
\hline MCV & $\mathrm{fL}$ & $62.08 \pm 1.96$ & $61.37 \pm 2.58^{\mathrm{ns}}$ & $58.03 \pm 1.53^{\mathrm{ns}}$ & $47.83 \pm 3.18^{\star \star \star}$ \\
\hline $\mathrm{MCH}$ & pg & $17.43 \pm 0.29$ & $18.07 \pm 0.86^{\mathrm{ns}}$ & $16.80 \pm 0.96^{\mathrm{ns}}$ & $17.40 \pm 0.57^{\mathrm{ns}}$ \\
\hline MCHC & $\mathrm{g} / \mathrm{dL}$ & $30.60 \pm 0.90$ & $28.80 \pm 0.51^{\mathrm{ns}}$ & $28.63 \pm 1.63^{\mathrm{ns}}$ & $30.77 \pm 0.23^{\mathrm{ns}}$ \\
\hline Platelets & $10^{3} / \mu \mathrm{l}$ & $6.10 \pm 1.51$ & $6.20 \pm 0.78^{\text {ns }}$ & $5.30 \pm 1.95^{\mathrm{ns}}$ & $7.80 \pm 0.15^{\mathrm{ns}}$ \\
\hline
\end{tabular}

Values are expressed as mean $\pm \operatorname{SEM}\left(\mathrm{n}=3\right.$ for each group). ${ }^{*} \mathrm{P}<0.05,{ }^{* *} \mathrm{P}<0.01,{ }^{* * *} \mathrm{P}<0.001$ were considered significant. Asterisks denote significant difference compared to control.

HB: Hemoglobin; PNL: Polymorphonuclear leukocytes; RBC: Red blood cells; PCV: Packed cell volume; MCV: Mean corpuscular volume; MCH: Mean corpuscular hemoglobin; MCHC: Mean corpuscular hemoglobin concentration, ns: Not significant. 


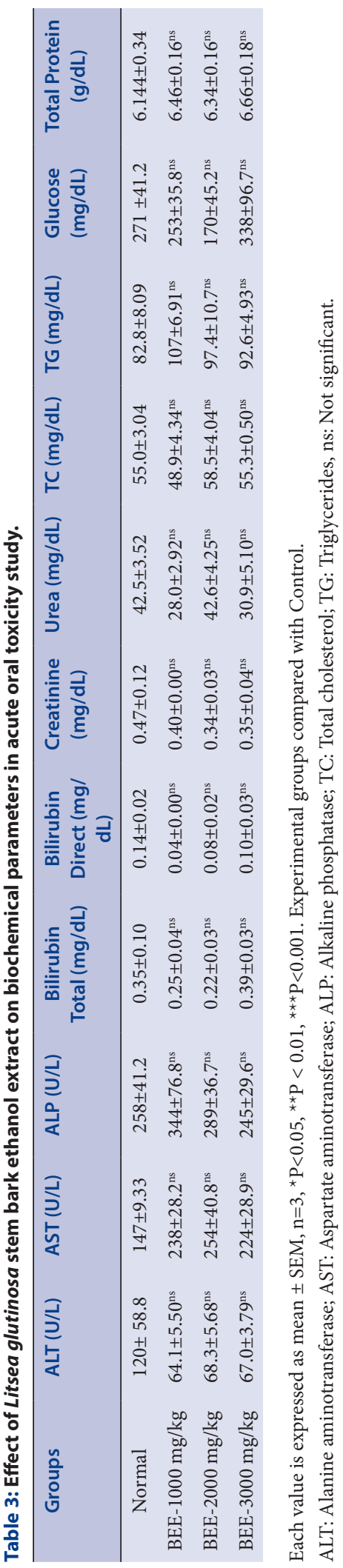

gains were observed in all animals administered with stem BEE of L. glutinosa. It can be stated that the BEE did not interfere with the normal metabolism of animals as corroborated by the non-significant difference from animals in the vehicle control group. The significant increment in food and water intake is considered as being responsible for the increment in b.w. gain. As mentioned earlier the loss of appetite is often synonymous with weight loss due to disturbances in the metabolism of carbohydrate, protein, or fat. ${ }^{26}$ Therefore, the normal food and water intake without loss of appetite are suggested as being responsible for the observed increment in b.w. in this study. In addition, the observed increase in b.w. could be attributed to the nutritive components in the $L$. glutinosa $\mathrm{BEE}{ }^{26,27}$

Blood parameters were also evaluated for hematological toxicity after 14 days. The rats in the BEE treated groups did not show any appreciable changes in their blood parameters when compared to that of the control, suggesting that the extract has no adverse effect on haematopoiesis and other blood cell formations. In serum biochemical parameter evaluation, liver toxicity can be detected by the measurement of various liver enzymes, particularly the levels of ALT, AST and ALP. ALT is a cytoplasmic enzyme and found at a high level in the liver. Elevation in the ALT level indicates the liver cell damage. ${ }^{28}$ AST and ALP are present in many of the vital organs and also serves as an indicator for liver function. Biliary occlusion and damage can be confirmed by the alteration in the serum bilirubin level. Kidney function is also an important aspect to indicate the potential toxicity of a compound. The level of creatinine is an indicator of the kidney function. An elevation in its level indicates the impaired glomerular filtration and kidney damage. ${ }^{29}$ Serum urea elevation is an indicator for various tissue injuries such as cardiac, renal parenchymal and renal calculi. Alterations in the normal metabolism of animals can be evaluated by the measurement of glucose and lipids. ${ }^{30}$ The level of glucose, total cholesterol, and triglycerides were measured and none of these parameters showed significant values between the stem BEE treated and normal groups, indicating that the extract has no deleterious effect on the vital organs. The histopathological study also revealed that the liver of rats treated with BEE did not show any pathological alterations (necrosis, inflammation, or fibrosis) and no macrophages were found. No specific changes were detected in the liver parenchyma and were similar to the control group.

\section{CONCLUSION}

The current study is valuable since it could indicate about the non-toxic parts of the plant may help to employ the plant as an antimicrobial or antioxidant agent. L. glutinosa stem bark ethanol extract was found to be nontoxic when acute oral toxicity study was performed. These results may primarily suggest L. glutinosa BEE to be consumed as a drug to treat liver diseases (Jaundice), diarrhea and dysentery in known dosages, especially in poor rural communities, where conventional drugs are expensive and unaffordable.

\section{ACKNOWLEDGEMENT}

This work was supported by the DBT New Delhi [F No. BT/PR/9128/ INF/22/190/2013, Dated: 30/06/2015]. The authors thank to Prof. Y L Krishna murthy, Department of Applied Botany and the administrative authority Kuvempu University for providing facility to carried out the present study.

\section{CONFLICT OF INTEREST}

The authors declare that there is no conflict of interest. 


\section{ABBREVIATION USED}

BEE: Bark ethanol extract; b.w: Body weight; ATCC: American type culture collection; OECD: Organization of Economic Cooperation and Development; HB: Hemoglobin; RBC: Red blood cells; PCV: Packed cell volume; MCV: Mean corpuscular volume; $\mathbf{M C H}$ : Mean corpuscular hemoglobin; MCHC: Mean corpuscular hemoglobin concentration; ALT: Alanine aminotransferase; AST: Aspartate aminotransferase; ALP: Alkaline phosphatase; TC: Total cholesterol; TG: Triglycerides; NCI: National cancer institute; $\mathbf{L D}_{50}$ : Lethal Dose $50 \%$; ns: Not significant.

\section{REFERENCES}

1. Da-Costa LL, Albano F, Laranja AG, Marques AL, Silva LF, Souza GP, et al. Toxicological evaluation by in vitro and in vivo assays of an aqueous extract prepared from Echinodorus macrophyllus leaves. Toxicol Lett. 2000;116(3):189-98.

2. Stein U, Greyer H, Hentschel H. Nutmeg (myristicin) poisoning--report on a fatal case and a series of cases recorded by a poison information centre. Forensic Sci Int. 2001;118(1):87-90

3. Wirth JH, Hudgins JC, Paice JA. Use of Herbal Therapies to Relieve Pain: A Review of Efficacy and Adverse Effects. Pain Manag Nurs. 2005;6(4):145-67.

4. Zhu M, Lew KT, Leung P. Protective effect of a plant formula on ethanol-induced gastric lesions in rats. Phyther Res. 2002;16(3):276-80

5. Grever, MCB. Cancer drug discovery and development. In: De Vita, V.H.S. and Rosenberg, S.A, (eds.) Cancer: Principles and practice of oncology. Philadelphia, Lippincott Raven.2001;328-39.

6. Peters GJ, Backus HHJ, Freemantle S, Triest B, Codacci-Pisanelli G, der-Wilt CL, et al. Induction of thymidylate synthase as a 5-fluorouracil resistance mechanism. Biochem Biophys Acta. 2002;1587(2-3):194-205.

7. Eloff JN. Which extractant should be used for the screening and isolation of antimicrobial components from plants?. J Ethnopharmacol. 1998;60(1):1-8

8. Pradeepa K, Krishna V, Venkatesh, Santosh KSR, Girish KK. Antinociceptive property of leaves extract of Litsea glutinosa. Asian J. Pharm. Clin. Res. 2013; 6(1)182-4

9. Haque T, Uddin MZ, Saha ML, Mazid MA, Hassan MA. Propagation, antibacterial activity and phytochemical profiles of Litsea glutinosa (Lour.) C. B. Robinson. Dhaka Univ J Biol Sci. 2014;23(2):165-71.

10. Arunodaya HS, Krishna V, Shashikumar R, Girish Kumar K. Antibacterial and antioxidant activities of stem bark essential oil constituents of Litsea glutinosa C B. ROB. Int J Pharm Pharm Sci. 2016;8(12):258-64

11. Bhowmick R, Sarwar MS, Dewan SMR, Das A, Das B, Uddin MMN, et al. In vivo analgesic, antipyretic, and anti-inflammatory potential in Swiss albino mice and in vitro thrombolytic activity of hydro-alcoholic extract from Litsea glutinosa leaves. Biol Res. 2014;47(1):56

12. Asima Chatterjee and Satyesh Chandra Pakrashi. Treatise on Indian Medicinal Plants - 6 Volumes by Asima Chatterjee at Vedic Books. Publ. Inf. Dir.1994;107.

13. Cetin $Y$, Bullerman LB. Cytotoxicity of Fusarium mycotoxins to mammalian cell cultures as determined by the MTT bioassay. Food Chem Toxicol. 2005; 43(5):755-64.

14. OECD guideline 423. OECD guideline for testing of chemicals. Acute Oral Toxicity-Acute Toxic Class Method; 2001;1-14.

15. Babu PS, Krishna V, Maruthi KR, Shankarmurthy K, Babu RK. Evaluation of acute toxicity and hepatoprotective activity of the methanolic extract of Dichros tachyscinerea (Wight and Arn.) leaves. Pharmacognosy Res. 2011;3(1):40-3.

16. Balijepalli MK, Suppaiah V, Chin AM, Buru AS, Sagineedu SR, Pichika MR. Acute oral toxicity studies of Swietenia macrophylla seeds in Sprague Dawley rats. Pharmacognosy Res. 2015;7(1):38-44.

17. Lia Ardiana, Meiliza Ekayanti, Sarah Zielda Najib, Rani Sauriasari, BernaElya. Preliminary acute oral toxicity study of white tea leaf (Camellia sinensis (L.) Kuntze) Ethanolic Extracts. Pharmacogn J. 2017;9(4):479-82.

18. Sahgal G, Ramanathan S, Sasidharan S, Mordi MN, Ismail S, Mansor SM. Brine shrimp lethality and acute oral toxicity studies on Swietenia mahagoni (Linn.) Jacq. Seed methanolic extract. Pharmacognosy Res. 2010;2(4):215-20.

19. Turner DM. Natural product source material use in the pharmaceutical industry: the Glaxo experience. J Ethnopharmacol. 1996;51(1-3):39-43; discussion 44.

20. Wonder KMA, George KA, Eric BG. Acute and sub-acute toxicity studies of the ethanolic extract of the aerial parts of Hilleria latifolia (Lam) H.Walt. (Phytolaccaceae) in rodents. West African J Pharmacy. 2011;22:27-35.

21. Suffness M, and Pezzuto JM. Assays related to cancer drug discovery. In Methods in plant biochemistry: Assays for bioactivity, ed. K. Hostettamann. London: Academic Press. 1990;6:71-133.

22. Wang YS, Liao Z, Li Y, Huang R, Zhang HB, Yang JH. A new megastigmane diglycoside from Litsea glutinosa (Lour.) C. B. Rob. J Braz Chem Soc. $2011 ; 22(11): 2234-8$

23. Agrawal N, Pareek D, Dobhal S, Sharma MC, Joshi YC, Dobhal MP. Butanolides from Methanolic Extract of Litsea glutinosa. Chem Biodivers. 2013;10(3):394-400.

24. Ghosh N, Chaki R, Pal M, Mandal SC. Hepatoprotective activity of methanol extract of Litsea glutinosa against hepatotoxin induced toxicity. Orient Pharm Exp Med. 2016;16(2):139-46.

25. Hilaly J El, Israili ZH, Lyoussi B. Acute and chronic toxicological studies of Ajugaiva in experimental animals. J Ethnopharmacol. 2004;91(1):43-50.

26. Ezeonwumelu JOC, Julius AK, Muhoho CN, Ajayi AM, Oyewale AA, Tanayen JK et al. Biochemical and histological studies of aqueous extract of Bidenspilosaleaves from Ugandan Rif Valley in Rats. Br J Pharmacol Toxicol. 2011;2(6):302-9.

27. Duke JA. The green pharmacy: new discoveries in herbal remedies for common diseases and conditions from the world's foremost authority on healing herbs. Rodale Press. 1997.

28. Wang TC, Su YP, Hsu TY, Yang CC, Lin CC. 28-Day oral toxicity study of the aqueous extract from spider brake (Pteris multifida Poiret) in rats. Food Chem Toxicol. 2007;45(9):1757-63.

29. Rhiouani H, El-Hilaly J, Israili ZH, Lyoussi B. Acute and sub-chronic toxicity of an aqueous extract of the leaves of Herniaria glabra in rodents. J Ethnopharmacol. 2008;118(3):378-86

30. Seiva FRF, Chuffa LGA, Braga $C P$, Amorim JPA, Fernandes $A A H$. Quercetin ameliorates glucose and lipid metabolism and improves antioxidant status in postnatally monosodium glutamate-induced metabolic alterations. Food Chem Toxicol. 2012:50(10):3556-61.

\section{GRAPHICAL ABSTRACT}

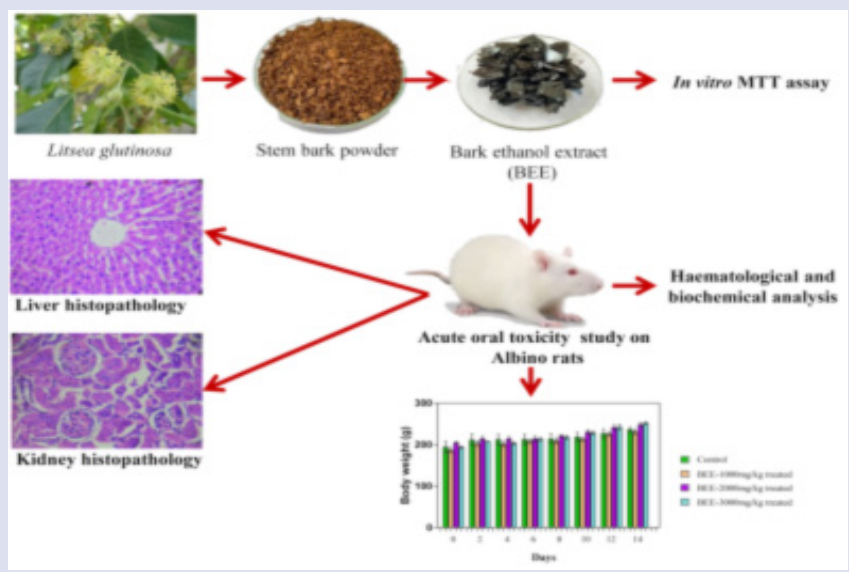

\section{SUMMARY}

- Evaluation of cytotoxicity and oral acute toxicity of L. glutinosa stem BEE was performed for a period of 14 days

- BEE did not show any significant cytotoxic effect against the tested cell lines. Whereas, acute toxicity study of BEE showed no deaths or any sign of toxicity up to a dose of $3000 \mathrm{mg} / \mathrm{kg} \mathrm{b.w.} \mathrm{In} \mathrm{addition,} \mathrm{there} \mathrm{was} \mathrm{no} \mathrm{change} \mathrm{in} \mathrm{hemato-}$ logical, biochemical and histological investigation.

- The present study shows that the oral administration of BEE was found to be safe. 


\section{ABOUT AUTHORS}

Mr. Arunodaya H S, Research Scholar, Department of Biotechnology, Kuvempu University. He is having three years of teaching and six years of research experience. He has published two research articles in peer reviewed journals.

Dr. V Krishna, Professor, Department of PG studies and research in Biotechnology, Kuvempu University. He is having 27 years of teaching and research experience in the field of Plant tissue culture, Phytochemistry and Pharmacology. He is currently running 5 crore project and has received research grants from various funding agencies like DBT, DST, UGC etc. He has published 185 research papers in international and national peer reviewed journals. He is having one patent to his credit.

Dr. Kumaraswamy H M, Assistant professor, Department of Biotechnology, Kuvempu University. He has more than 10 year of research and teaching experience in the field of Phytochemistry, Pharmacology and Cancer biology. He has received research grants from various agencies like DBT, UGC etc., He has published 16 research articles in international and national peer reviewed journals.

Mr. Vinaykumar N M, Research Scholar, Department of Biotechnology, Kuvempu University. He is having one year of research experience.

Cite this article: Arunodaya HS, Venkatarangaiah K, Kumaraswamy HM, Vinaykumar NM. Cytotoxicity and Oral Acute Toxicity Studies of Litsea glutinosa C. B (ROB) Stem Bark Ethanol Extract. Pharmacog J. 2017;9(6):880-6. 